Delft University of Technology

\title{
A CMOS Temperature Sensor with a 49fJ·K2 Resolution FoM
}

Pan, Sining; Jiang, Hui; Makinwa, Kofi A.A.

DOI

10.23919/vlsic.2017.8008557

Publication date

2017

Document Version

Accepted author manuscript

Published in

Digest of Technical Papers - 2017 Symposium on VLSI Circuits

\section{Citation (APA)}

Pan, S., Jiang, H., \& Makinwa, K. A. A. (2017). A CMOS Temperature Sensor with a 49fJ.K2 Resolution FoM. In Digest of Technical Papers - 2017 Symposium on VLSI Circuits (pp. C82-C83). IEEE .

https://doi.org/10.23919/vlsic.2017.8008557

\section{Important note}

To cite this publication, please use the final published version (if applicable).

Please check the document version above.

\section{Copyright}

Other than for strictly personal use, it is not permitted to download, forward or distribute the text or part of it, without the consent of the author(s) and/or copyright holder(s), unless the work is under an open content license such as Creative Commons.

\section{Takedown policy}

Please contact us and provide details if you believe this document breaches copyrights.

We will remove access to the work immediately and investigate your claim. 


\title{
A CMOS Temperature Sensor with a $49 \mathrm{fJ} \cdot \mathrm{K}^{2}$ Resolution FoM
}

\author{
Sining Pan, Hui Jiang, Kofi A.A. Makinwa
}

Delft University of Technology, Delft, the Netherlands

\begin{abstract}
This paper presents the most energy-efficient CMOS temperature sensor ever reported, with a resolution FoM of $49 \mathrm{fJ} \cdot \mathrm{K}^{2}, 2.7 \times$ better than the state-of-the-art. It consists of a Wheatstone bridge made from poly-silicon resistors, which is readout by a $2^{\text {nd }}$-order Continuous-Time Delta-Sigma modulator (CTDSM). This approach leads to a high resolution $(160 \mu \mathrm{K}$ in $10 \mathrm{~ms})$ and a low supply-voltage sensitivity $(<20 \mathrm{mK} / \mathrm{V}$ at room temperature).
\end{abstract}

\section{Introduction}

Temperature compensation schemes are essential parts of high-performance frequency references $[1,2]$. To obtain low jitter and low power consumption, the associated temperature sensors must achieve both high resolution and energy efficiency. These requirements can be met by resistor-based temperature sensors, typically consisting of either Wheatstone [1,3] or Wien bridges [4, 5].

Wheatstone bridges can be built from resistors with temperature coefficients (TCs) of opposite polarity, and so are more sensitive, and hence, more energy-efficient than Wien bridges, which employ a single type of resistor and a stable capacitive impedance. Moreover, unlike Wien bridges, which require a known reference frequency, Wheatstone bridges are self-referenced. In terms of energy efficiency, however, the state-of-the-art is defined by a Wien bridge sensor, which achieved a resolution FoM of $0.13 \mathrm{pJ} \cdot \mathrm{K}^{2}$ [4]. This paper presents a Wheatstone bridge sensor whose resolution FoM is $2.7 \times$ better.

\section{Proposed Design}

As shown in Fig. 1a, the proposed temperature sensor consists of a Wheatstone bridge made out of a silicided p-poly (s-p-poly) resistor $\left(\mathrm{R}_{\mathrm{p}}=105 \mathrm{k} \Omega\right.$, positive TC) and a non-silicided n-poly resistor $\left(\mathrm{R}_{\mathrm{n}}=95 \mathrm{k} \Omega\right.$, negative $\left.\mathrm{TC}\right)$. Compared to diffusion resistors [3], the s-p-poly resistor has a larger TC and a near-zero voltage dependency. To investigate the performance of the p-poly resistor, a bridge made from s-p-poly and p-poly resistors was also realized. Its resistances $\left(\mathrm{R}_{\mathrm{p}}=67.5 \mathrm{k} \Omega, \mathrm{R}_{\mathrm{n}}=64 \mathrm{k} \Omega\right)$ are chosen to match the sensitivity of the $\mathrm{s}-\mathrm{p} / \mathrm{n}$-poly bridge over the industrial temperature range $-40^{\circ} \mathrm{C}$ to $85^{\circ} \mathrm{C}$.

Current readout of a Wheatstone bridge, however, suffers from systematic non-linearity (NL). In the case when $\mathrm{R}_{\mathrm{p}}(\mathrm{T})=$ $\mathrm{R}_{\mathrm{p}}\left(\mathrm{T}_{0}\right) \cdot(1+\alpha \Delta \mathrm{T})$ and $\mathrm{R}_{\mathrm{n}}(\mathrm{T})=\mathrm{R}_{\mathrm{n}}\left(\mathrm{T}_{0}\right)=\mathrm{R}_{\mathrm{p}}\left(\mathrm{T}_{0}\right)$, i.e. the $\mathrm{TC}$ of $R_{n}$ is much smaller than that of $R_{p}$, the bridge's output current will be given by:

$$
\mathrm{I}_{\text {out }}=\frac{\mathrm{V}_{\mathrm{DD}}}{2}\left(\frac{1}{\mathrm{R}_{\mathrm{p}}\left(\mathrm{T}_{0}\right) \cdot(1+\alpha \Delta \mathrm{T})}-\frac{1}{\mathrm{R}_{\mathrm{n}}\left(\mathrm{T}_{0}\right)}\right) \text {, }
$$

For an $s-p / p$ poly bridge, simulations based on the TC specified by the foundry then result in a systematic NL of about $13^{\circ} \mathrm{C}$ after a $1^{\text {st }}$-order fit, (Fig. $1 b$ ).

As in [3], the Wheatstone bridge sensors are read out by connecting them to the virtual ground of the $1^{\text {st }}$ integrator of a CTDSM (Fig. 2). The modulator's resistive DAC $\left(R_{D A C}=140 \mathrm{k} \Omega\right)$ will then null their output current. In this read-out scheme, the bitstream average is only determined by the ratios between $R_{p}, R_{n}$ and $R_{D A C}$ (same type as $R_{n}$ ) and so is independent of the supply voltage. To minimize its input impedance, the $1^{\text {st }}$ integrator is based on an Opamp rather than an OTA. For energy-efficiency, the modulator employs a $2^{\text {nd }}$-order feedforward topology, with the feedforward factor implemented by $\mathrm{R}_{\mathrm{ff}}$ (Fig. 2).

In this work, in contrast to [3], the offset and $1 / f$ noise of the $1^{\text {st }}$ integrator are suppressed by chopping. To avoid aliasing high-frequency quantization noise at the chopping transitions [6], the chopping frequency is the same as the sampling frequency $(500 \mathrm{kHz})$.

The opamp of the $1^{\text {st }}$ integrator is a two-stage design consisting of a telescopic OTA and two PMOS source followers, while the $2^{\text {nd }}$ integrator consists of a telescopic OTA with a source-degenerated NMOS input pair. From simulations, the $1^{\text {st }}$ and $2^{\text {nd }}$ integrators dissipate $100 \mu \mathrm{W}$ and $7 \mu \mathrm{W}$, respectively, from a $1.8 \mathrm{~V}$ supply. The bridges dissipate $32 \mu \mathrm{W}$ (s-p/n-poly) and $25 \mu \mathrm{W}$ (s-p/p-poly).

\section{Measurement results}

The two Wheatstone bridge sensors were fabricated side-by-side in a TSMC 180nm process (Fig. 3). They share the same clock and constant- $g_{m}$ biasing circuits and each occupy $0.72 \mathrm{~mm}^{2}$, which is dominated by the large capacitors $(2 \times 180 \mathrm{pF})$ of the $1^{\text {st }}$ integrator. For flexibility, the $\operatorname{sinc}^{2}$ decimation filter is realized off-chip.

Twenty samples from one wafer were characterized in ceramic packages from $-45^{\circ} \mathrm{C}$ to $85^{\circ} \mathrm{C}$ in a temperature-controlled oven. For stable measurements, the samples are placed inside an aluminum block, which reduces temperature fluctuations to the $1 \mathrm{mK}$ level. The bitstream averages of the two sensors are shown in Fig. 4. After a $1^{\text {st }}$-order fit, the measured NL agrees well with simulations (Fig. 1b), indicating that it is indeed mainly due to the current readout scheme. After removing this systematic NL, the resulting spread is below $0.07^{\circ} \mathrm{C}(3 \sigma)$ for the $s-p / p$-poly sensor, and below $0.10^{\circ} \mathrm{C}(3 \sigma)$ for the s-p/n-poly sensor. In a conversion time $\left(\mathrm{T}_{\text {conv }}\right)$ of $10 \mathrm{~ms}$, the $\mathrm{s}-\mathrm{p} / \mathrm{n}$-poly sensor achieves a thermal-noise limited resolution of $164 \mu \mathrm{K}$ (Fig. 5) The observed $1 / f$ noise is mainly due to the non-silicided poly resistors [4], resulting in a $10 \mathrm{~Hz}$ corner frequency for both sensors. At room temperature, the power supply sensitivities of both sensors is less than $16 \mathrm{mK} / \mathrm{V}$ (Fig. 6).

In Table I, the performance of the proposed temperature sensor is summarized and compared to the state-of-the-art. Its $49 \mathrm{fJ} \cdot \mathrm{K}^{2}$ resolution FoM is $2.7 \times$ better than that of [4], and is similar to that of a recent MEMS-based sensor [2]. Also, its power-supply sensitivity is close to a state-of-the-art BJT-based sensor [7].

\section{References}

[1] M. H. Perrott et al., JSSC, Jan. 2013.

[2] M. H. Roshan et al., JSSC, Jan. 2017.

[3] C. H. Weng et al., JSSC, Nov. 2015.

[4] S. Pan et al., ISSCC, Feb. 2017. in press.

[5] P. Park et al., JSSC, Apr. 2015.

[6] S. Billa et al., ISSCC, Feb. 2016.

[7] B. Yousefzadeh et al., Circ. Symp VLSI, June. 2016. 


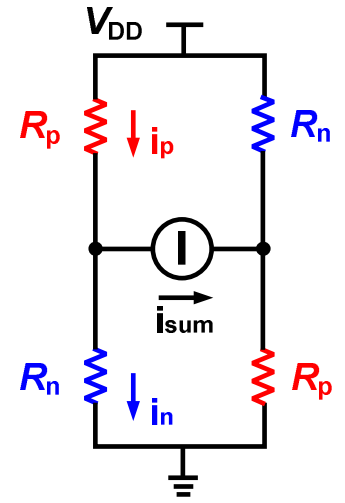

(a)

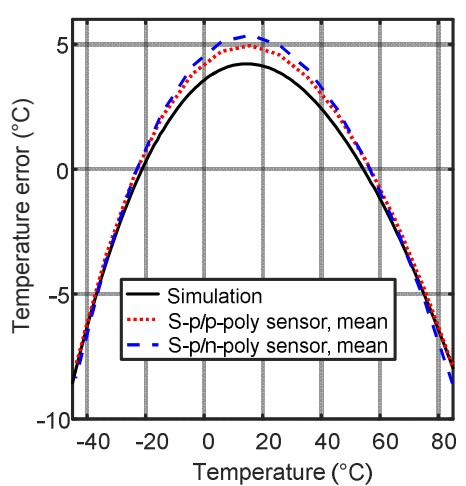

(b)
Fig. 1. (a) Wheatstone bridge sensor front-end with current readout scheme; (b) Measured and simulated NL for the two current-readout Wheatstone bridge sensors, after a $1^{\text {st }}$-order fit.

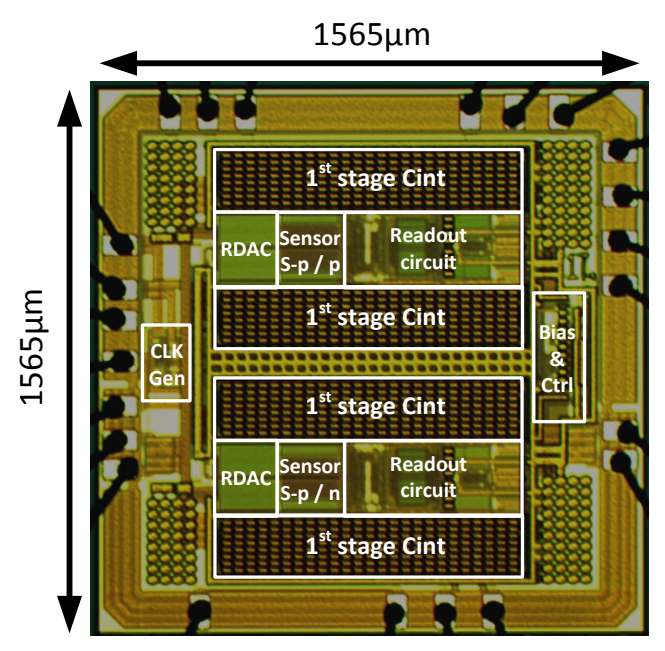

Fig. 3. Die micrograph of two side-by-side sensors.

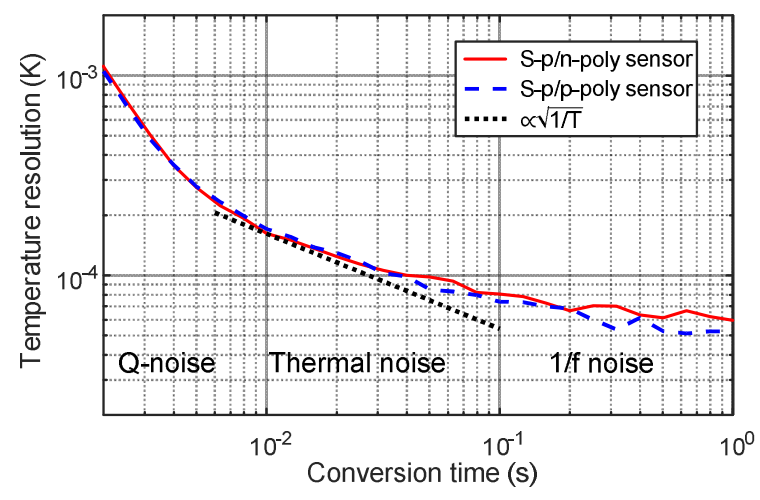

Fig. 5. Resolution vs. conversion time at room temperature.

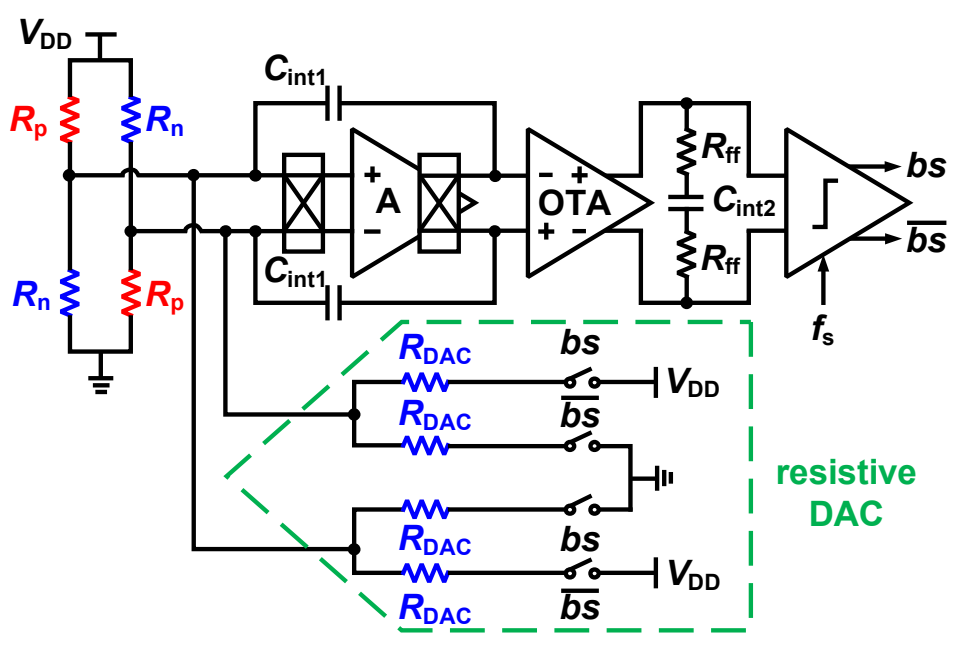

Fig. 2. Full system block diagram.
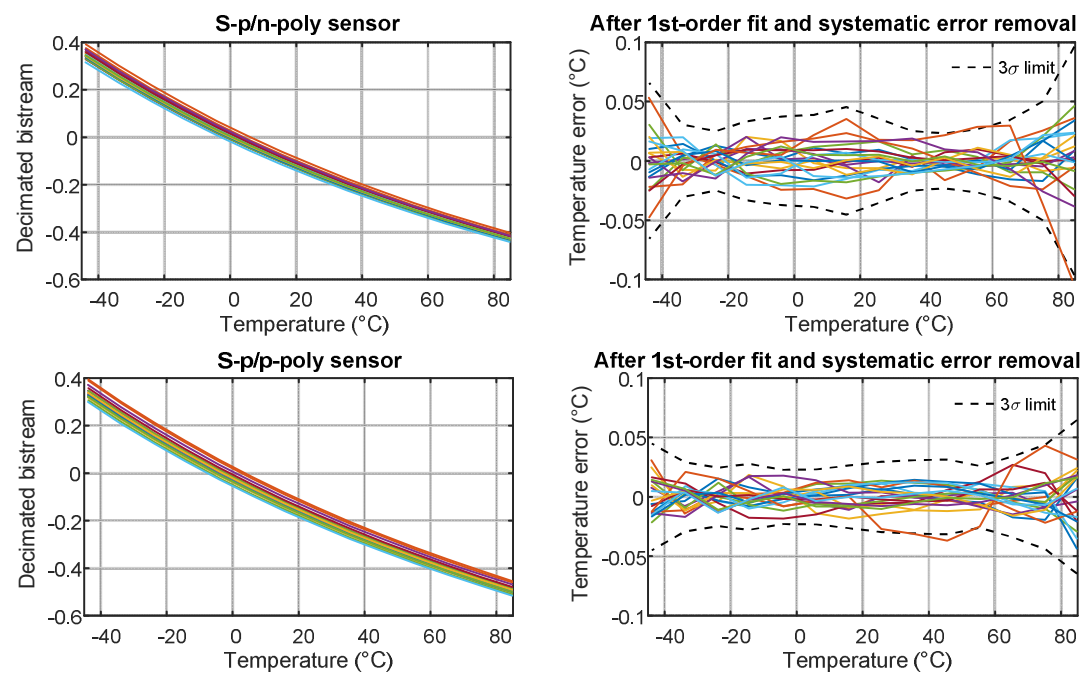

Fig. 4. Decimated bitstream vs. temperature (left) and temperature error (right) after $1^{\text {st }}$-order fitting and systematic NL removal for s-p/n-poly (top) and s-p/p-poly (bottom) sensors.

TABLE I. Performance summary and comparison with the state-of-the-art

\begin{tabular}{|c|c|c|c|c|c|c|c|c|c|c|c|}
\hline & Sensor type & $\begin{array}{c}\text { Tech } \\
(\mu \mathrm{m})\end{array}$ & $\begin{array}{c}\text { Area } \\
\left(\mathrm{mm}^{2}\right)\end{array}$ & $\begin{array}{c}\text { Power } \\
(\mathrm{mW})\end{array}$ & $\begin{array}{c}\text { T. Range } \\
\left({ }^{\circ} \mathrm{C}\right)\end{array}$ & $\begin{array}{c}\text { Resolution } \\
(\mathrm{mK})\end{array}$ & $\begin{array}{c}\mathrm{T}_{\text {conv }} \\
(\mathrm{ms})\end{array}$ & $\begin{array}{c}\text { Trim } \\
\text { points }\end{array}$ & $\begin{array}{c}\text { Inaccuracy } \\
( \pm 3 \sigma \text { error })\end{array}$ & $\begin{array}{c}\text { PSS } \\
\left({ }^{\circ} \mathrm{C} / \mathrm{V}\right)\end{array}$ & $\begin{array}{c}\text { Res. FoM } \\
\left(\mathrm{pJ} \cdot \mathrm{K}^{2}\right)\end{array}$ \\
\hline $\begin{array}{c}\text { This } \\
\text { work }\end{array}$ & Resistor & 0.18 & 0.72 & 0.18 & $-40-85$ & 0.16 & 10 & $2^{\mathrm{a}}$ & $\pm 100 \mathrm{mK}$ & 0.016 & 0.049 \\
\hline$[4]$ & Resistor & 0.18 & 0.72 & 0.16 & $-40-85$ & 0.41 & 5 & $2^{\mathrm{a}}$ & $\pm 70 \mathrm{mK}$ & -0.17 & 0.13 \\
\hline$[1]$ & Resistor & 0.18 & 0.18 & 13 & $-40-85$ & 0.1 & 100 & 6 & $\pm 15 \mathrm{mK}^{\mathrm{c}}$ & -- & 13 \\
\hline$[3]$ & Resistor & 0.18 & 0.43 & 0.065 & $-40-125$ & 10 & 0.1 & $2^{\mathrm{b}}$ & $\pm 400 \mathrm{mK}^{2}$ & 0.4 & 0.65 \\
\hline$[5]$ & Resistor & 0.18 & 0.09 & 0.031 & $-40-85$ & 2.8 & 32 & 3 & $\pm 120 \mathrm{mK}^{\mathrm{c}}$ & -0.4 & 8 \\
\hline$[7]$ & BJT & 0.16 & 0.16 & 0.007 & $-70-125$ & 15 & 5 & 1 & $\pm 60 \mathrm{mK}$ & 0.01 & 7.3 \\
\hline$[2]$ & Dual-MEMS & 0.18 & 0.54 & 19 & $-40-105$ & 0.02 & 5 & -- & -- & -- & 0.04 \\
\hline
\end{tabular}

${ }^{\mathrm{a}} 1^{\text {st }}$-order fit. ${ }^{\mathrm{b}} 1$-point trim with $1^{\text {st }}$-order curve fitting. ${ }^{\mathrm{c}}$ Min or Max. 